\title{
Covid-19, Vaccination and Labour Discrimination
}

\section{Rodriguez Cardo IA* \\ Labour Law and Social Security, University of Oviedo, Spain}

*Corresponding author: Ivan Antonio Rodríguez Cardo, Associate Professor, Labour Law and Social Security, University of Oviedo, Spain, Email: rodriguezivan@uniovi.es

\section{Conceptual Paper}

Volume 4 Issue 3

Received Date: June 15, 2021

Published Date: July 20, 2021

DOI: $10.23880 /$ abca-16000187

\section{Abstract}

The aim of this paper is to provide a first approach to the possible discriminatory nature of the employer's decisions motivated by the refusal of the employee to be vaccinated against COVID (or by the decision of being vaccinated, even if those situations are rare). This is a sensible issue, because Labour Law does not usually provide a straightforward answer and fundamental rights are at stake (health, privacy, equality and non-discrimination and even the right to protection of personal data).

Keywords: General Data Protection Regulation; COVID-19 pandemic; Labour Discrimination

\section{General Overview}

The COVID-19 pandemic has had a great impact all over the world. With the purpose of slowing down the spread of the virus and controlling the situation, Governments have imposed restrictions to people's movement and social contact (including temporary confinement of the population at home). Most economic and working activities were temporarily paralysed, at least for a while, leaving apart those considered 'essential services'.

With the aim of reducing the economic and social impact of such extraordinary circumstances, protecting workers and allowing the resume of working activities after the crisis, a large list of measures has been implemented in the area of Labour Law and Social Security. Among others, promoting telework, facilitating the adaptation of working time to family care needs, favouring the temporary suspension of employment contracts or the reduction of working time, or adapting and enhancing unemployment benefits and other forms of social protection.

Obviously, economy has suffered a serious setback since March 2020, either as a direct result of the stoppage of certain businesses, or, indirectly, due to the consequences of the limitations on freedom of movement. The impact on people's life and the consequences in economy have been huge, so the announcement of effective vaccines against COVID-19 was a major development not only in terms of public health, but also particularly in terms of hope. Vaccines have been considered as the best chance to end the pandemic and to end it fast. Governments have started a race to provide vaccines, with the aim to return to 'normality' as soon as possible. However, the controversy on the effectiveness of the vaccines and their allegedly side-effects have led to certain refusal of the vaccination.

In this moment, June 2021, certain countries, and even the European Union, have announced that restrictions could be gradually lifted for people vaccinated. The EU has a proposal for a Regulation "on a framework for the issuance, verification and acceptance of interoperable certificates on vaccination, testing and recovery to facilitate free movement during the COVID-19 pandemic (Digital Green Certificate)", with the aim to boost the freedom of movement with immediate effects.

Without any doubt, this kind of measures will reach 
employment relationships (has already reached this field, in fact). Vaccination (or the lack of) will be taking into account for hiring workers or even for dismissals. This is a sensible issue, because Labour Law does not usually provide a straightforward answer, and fundamental rights are at stake (health, privacy, equality and non-discrimination and even the right to protection of personal data). The aim of this paper is to provide a first approach to the possible discriminatory nature of the employer's decisions motivated by the refusal of the employee to be vaccinated (or by the decision of being vaccinated, even if those situations are rare).

\section{Discrimination on Grounds of Disease: the Speciality of COVID}

In many countries (i.e., Spain), the employer decision to terminate an employment contract of a worker in temporary disability is not per se discriminatory. The courts have considered that illness is not a valid ground for discrimination, at least illness as a generic category. Sure, this statement is not entirely true after CJEU rulings HK Danmark [1], Fag og Arbejde (FOA) [2] and Daouidi [3], because an illness that provokes long-term limitations is considered as a disability, and disabled people are heavily protected by anti-discrimination laws. Discrimination on the grounds of disability is simply forbidden. However, these rulings introduce an exception and have their own scope of application, so, as a general rule; an illness is not one of the grounds taking into account by anti-discrimination laws of course, a dismissal on grounds on disease is not allowed, but it is not discriminatory, only unlawful. That means that, in these countries, the employer can terminate the contract paying a severance pay, but the worker has no right to be reinstated. When the dismissal is discriminatory (for instance, due to race, gender, disability, etc.) the judge qualifies it as null and void, and the worker has the right to return to his/her job.

Could these rules apply to COVID? The so-called long COVID (the term refers to situations where symptoms persist for months) fits in that definition of disability provided by the CJEU $[4,5]$. However, a different approach is needed regarding situations that are more usual in practice. Unlike other diseases, COVID has caused substantial changes in the way people live and relate to each other. This is a unique feature of COVID, at least recently, and has a decisive influence in the assessment of its impact. Other diseases may have more serious consequences either in terms of the physical limitations they cause, in terms of their long-term effects or even in terms of higher mortality. However, these conditions usually affect those who suffer from the pathology in question, a small percentage of the population, with no real consequences for the rest of society. COVID, on the other hand, not only has a direct impact on those infected, but also on everyone else, as the measures to combat the disease are compulsory for public health reasons and involve a very intense modulation of fundamental rights (e.g. restrictions on mobility or the right of assembly, social distance, obligation to wear a mask, etc). Consequently, COVID has disrupted the ordinary life of everyone, and that, of course, has increased the general desire to overcome the pandemic in the shortest possible time.

There is no doubt that COVID has become a stigmatising disease, as UNESCO has pointed out [6]. Consequently, COVID is a disease with a high potential to become a cause of discrimination, both in general and in the context of the employment relationship. It is not surprising that the ILO has published recommendations on 'Addressing stigma and discrimination in the COVID-19 response' [7]. These recommendations build on the recommendations developed to prevent HIV and AIDS discrimination.

\section{COVID Discrimination at Work: Different} Scenarios

From an economic and organisational perspective, it is understandable that employers aim to achieve a COVIDfree working environment. The contagion of a worker is a problem for the undertaking, because it can even lead to a stoppage of the activity for public health reasons. Therefore, the employer has a legitimate business interest in taking measures to reduce the risk of COVID infection. However, these measures may collide with workers' rights, including fundamental rights.

Conflicts may arise even in the stages prior to entering into an employment contract. For example, the employer might ask the worker at the job interview if he/she has been sick with COVID or if he/she is vaccinated. This verification will be even easier thanks to the Digital Green Certificate, which is expected to become operational on 1 July 2021 [8]. This document tries to facilitate the right to free movement for people who theoretically do not pose a high risk of infection, mainly because they are vaccinated or have overcome the COVID. However, this certificate could be used with different purposes.

World Health Organisation has been sceptical about this kind of measures, because «there is not enough evidence about the effectiveness of antibody-mediated immunity to guarantee the accuracy of an "Immunity passport" or "riskfree certificate." People who assume that they are immune to a second infection because they have received a positive test result may ignore public health advice. The use of such certificates may therefore increase the risks of continued transmission. As new evidence becomes available, WHO will update this scientific brief» [9]. From a legal perspective, 
the European Data Protection Committee has expressed its concerns, because the Digital Green Certificate could lead to different treatment between individuals in their social life in general (e.g. access to certain establishments or places), and in the field of employment relations in particular [10].

The right to privacy and the anti-discrimination laws protect the worker in these situations. The employer cannot decide the hiring of a worker taking into account the COVID. This would be discrimination on grounds of a stigmatising disease. A dismissal for this very reason would be also discrimination. As ILO has pointed out, «one key aspect of the principle of non-discrimination and equality at work is that all employment decisions must be based on a person's capacity to per-form a job. If obesity or smoking, including beyond working hours and outside the workplace, is proven to affect the accomplishment of work-related tasks, not recruiting an overweight person or a smoker is in order. Similarly, obesity or smoking could be a valid motive for dismissal if it is detrimental to co-workers or other people whom the overweight person or smoker may interact with in his/her daily work. Otherwise denying a job or dismissing qualified persons solely on the basis of their obesity or because they are off-duty smokers would amount to discrimination and constitute an undue intrusion in their private life». These statements are equally valid for COVID [11].

\section{In Particular, COVID-19 Vaccines and Employment Relationship}

The COVID vaccination process is developing right now. It is important to point out that most countries have not imposed vaccination as an obligation, but as a right and a choice. The Governments organise the vaccination, but every person has the right to refuse the vaccine freely. There is no penalty for refusal, even in case of healthcare workers. From a legal point of view, not an ethical one [12], the Law could impose vaccination, as it has happened in Brazil and Italy $[13,14]$. The European Court of Human Rights has recently allowed mandatory vaccination for children if it is justified by pressing social needs [15], and the doctrine of this ruling seems to be appropriate for the COVID pandemic.

However, the Parliamentary Assembly of the Council of Europe, in its Resolution 2361 (2021), on Covid-19 vaccines: ethical, legal and practical considerations, «urges member States and the European Union to [...] ensure that citizens are informed that the vaccination is NOT mandatory and that no one is politically, socially, or otherwise pressured to get themselves vaccinated, if they do not wish to do so themselves [and to] ensure that no one is discriminated against for not having been vaccinated, due to possible health risks or not wanting to be vaccinated» [16].
In this context, most countries have given freedom to their population. A right to accept or refuse the vaccine. COVID has caused a public health crisis, so the State has a lead role in this process of vaccination. Even so, the undertakings have a legitimate aspiration to continue to operate under the best possible conditions. Thus, the employer could buy vaccines and offer them to the workers. There are three main- different legal problems arising. The first one, if the employer has the right to know if the workers are vaccinated. The second one, if the employer can force the worker to take the vaccine. The third one, if the employer can prevent the unvaccinated workers from continuing to work.

The answer depends of the regulatory framework of each particular country. Regarding question one, we could say that, in Europe, the General Data Protection Regulation (EU) 2016/679 (GDPR) does not allow the employer to know this kind of information related to health, because it is a special category of personal data (Article 9), heavily protected. Of course, this Article 9, paragraph (h), allows the processing of this data when 'is necessary for the purposes of preventive or occupational medicine, for the assessment of the working capacity of the employee, medical diagnosis, the provision of health or social care or treatment or the management of health or social care systems and services on the basis of Union or Member State law or pursuant to contract with a health professional and subject to the conditions and safeguards referred to in paragraph 3'. However, vaccination against COVID or against any other infectious disease- does not change the working capacity of the employee. The employer has the right to know if the worker retains the ability to perform the job, but this right does not give the employer unlimited access to medical records. The undertaking has the right to know if the worker pass or fail the medical examination, but not the particular medical diagnosis or details on the health status.

Concerning the second issue, the legislation on health and safety at work does not allow the employer to force vaccination, even in healthcare sector. Annex VII of Directive 2000/54/EC, of 18 September 2000, on the protection of workers from risks related to exposure to biological agents at work, includes a 'Recommended Code of Practice on Vaccination', according to which 'if the assessment referred to in Article 3(2) reveals that there is a risk to the health and safety of workers due to their exposure to biological agents for which effective vaccines exist, their employers should offer them vaccination'. It also states that 'vaccination must be offered free of charge to workers" and that workers 'should be informed of the benefits and drawbacks of both vaccination and non-vaccination'. Therefore, there is no room for mandatory vaccination in these activities exposed to biological agents (and no references for any other sectors) [17]. The employer cannot do it and neither collective 
bargaining. Mandatory vaccination has to be decided by Law.

The third issue is, maybe, the hardest one. Can the employer prevent an unvaccinated worker from continuing to work? The answer should be negative if the worker is healthy. Obviously, there are specific rules regarding workers infected by COVID, because they have to warn the employer and they are not allowed to work (they are protected by Social Security through temporary disability benefits). However, healthy workers cannot be dismissed and cannot suffer negative consequences for their refusal to be vaccinated. The reason alleged by the undertaking would be the risk of being infected in the future and spreading the disease at the employer premises, but this is simply fear of the disease.

Similar measures have been qualified as discriminatory, for example in the case of people living with HIV, as the European Court of Human Rights has warned in its ruling I.B. vs. Greece of 3 October 2013 [18]. If the employer cannot prevent an AIDS sufferer worker to perform his/her job, there are more solid legal reasons to protect an unvaccinated worker in this COVID context. There is discrimination on grounds of a stigmatising disease, even he/she is healthy, and this is a legitimate reason to activate the protection against employment discrimination.

\section{References}

1. (2013) Joined cases C-335/11 and C-337/11

2. (2014) Case C-354/13

3. (2016) Case C395/15.

4. (2019) Post-COVID Conditions. Centers for Diseases Control and Prevention.

5. (2019) Coronavirus disease (COVID-19). World Health Organization.

6. COVID-19-related discrimination and stigma: a global phenomenon?. UNESCO.
7. (2020) Addressing stigma and discrimination in the COVID-19 response: Key lessons from the response to HIV and AIDS. International Labour Organization, pp: $1-2$.

8. (2021) Regulation of the European Parliament and of the Council. European Commission, pp: 1-47.

9. (2020) "Immunity passports" in the context of COVID-19. World health Organization.

10. EDPB-EDPS Joint Opinion 04/2021 on the Proposal for a Regulation of the European Parliament and of the Council on a framework for the issuance, verification and acceptance of interoperable certificates on vaccination, testing and recovery. EDPB.

11. (2007) Equality at work: Tackling the challenges. Geneva, pp: 1-141.

12. Hoffman D, Mertzlufft J (2021) Ethics of Healthcare Personnel Declining Covid Vaccine Is it Ethical for Healthcare Professionals to Decline the Covid19 Vaccine if it is Available?. Annals of Bioethics \& Clinical Applications 4(2): 1-3.

13. http://www.stf.jus.br/portal/cms/verNoticiaDetalhe. asp?idConteudo $=457462$

14. (2021) Covid-19: Italy makes vaccination mandatory for healthcare workers. BMJ.

15. (2021) Case of Vavricka and others vs. Czech Republic. ECHR. Application no: 47621/13. Judgment.

16. (2021) Covid-19 Vaccines: Ethical, Legal and Practical Considerations. Parliamentary Assembly.

17. Villalón JC (2021) Instant Debate his Anti-Covid Vaccines and Employment Report: the Opinion of Jesús Cruz Villalon.

18. Case $552 / 10$. 